\title{
DESAIN DIFFUSER TURBIN AIR ARUS SUNGAI UNTUK MENINGKATKAN LAJU ARUS SUNGAI
}

\author{
${ }^{(1)}$ Rendi, ${ }^{(2)}$ Jainal Arifin \\ (1)(2)Teknik Teknik, Fakultas Teknik, Universitas Islam Kalimantan MAB \\ Jl. Adhiyaksa No. 2 Kayu Tangi, Banjarmasin \\ Email :rendi.teknikmesin@gmail.com, Jainalarifin804@gmail.com
}

\begin{abstract}
Abstrak
Arus air sungai cendrung memiliki kecepatan yang relatif rendah sehinggan tidak banyak turbin arus sungai yang bisa digunakan untuk membangkitkan tenaganya. Ada beberapa turbin yang sudah dilembangkan seperti turbin air rus sungai jenis Savonius, Darius dan Gorlof tetapi kinerja nya masih buruk. Kinerja turbin arus air dapat di tingkatkan dengan menambah kecepatan dan tekanan aliran air. Salah satu cara yang dapat digunakan untuk menambah kecepatan dan tekanan aliran air adalah dengan memasang diffuser pada turbin. Pada penelitian ini akan didesain sebuah difusser yang efektif untuk meningkatkan kinerja turbin arus sungai.
\end{abstract}

Kata kunci : Turbin arus air, diffuser, simulasi CFD

\begin{abstract}
River water flow has a relatively low speed so that not many river current turbines can be used to generate power. There are several turbines that have been developed such as Savonius, Darius and Gorlof river type water turbines, but their performance is still poor. Water flow turbine performance can be increased by increasing the speed and pressure of water flow. One way that can be used to increase the speed and pressure of water flow is by installing a diffuser on the turbine. In this study an effective diffusser will be designed to improve the performance of river flow turbines.
\end{abstract}

Keywords: Water current turbine, diffuser, CFD simulation

\section{PENDAHULUAN}

Indonesia adalah salah satu negara di dunia yang memili banyak sumbersumber energi alternatif khususnya energi alternatif yang bersumber dari tenaga air (hidro power). [1]

Pemanfaattan tenaga air (hidro power) pada umumnya memanfaatkan energi potensial yang diperoleh dari tinggi jatuh air (head air), semakin tinggi head air semakin besar energi potensial air yang bisa dimanfaatkan. Selain memanfaatkan energi potensial air (head air) ada juga yang memanfaatkan energi kinetik aliran air ini disebut sebagain turbin arus air atau hidrokinetik. Turbin arus air ini memanfaatkan aliran terbuka seperti memanfaatkan aliran sungai dan irigasi.[2]

Pengembangan turbin arus sungai mempunyai kelemahan yaitu kecepatan aliran sungai yang relatif kecil sehingga 
diperlukan suatu desain turbin arus sungai yang benar-benar efektif untuk memanfaatkan sekecil mungkin tenaga dari aliran sungai. Ada beberapa turbin arus sungai yang sudah di kemmbangkan seperti tirbin air Savonis, Darius dan helikal tetapi masih belum efektif di gunakan di aliran sungai kecendrungan nyahanya bisa dimanfaatkan di aliran yang berarus cepat.[3],[4]

Untuk menanfaatkan arus air sungai yang relatif kecil maka akad di kembangan turbin air yang memiliki diffuser yang dipasang pada turbin untuk meningkatkan kinerja turbin. pemasangan diffuser pernah dilakukan pada turbin angin yang memiliki kecepatan angin rendah hasilnya daya turbin akan meningkat beberpa kali lipat dibandingkan dengan turbin tampa diffuser. Namun tidak semua diffuser bisa digunakan malahan kalau desainnya tidak sesuai akan memper buruk kinerja turbin.[5]

Pada turbin air arus sungai penggunaan diffuser menjadi hal yang masih asing digunakan. Sehingga tidak banyak pengujian turbin arus sungaai menggunakan diffuser. Pada penelitian ini akan didesain sebuah difusser yang efektif untuk meningkatkan kinerja turbin arus sungai.[3]

\section{METODE PENELITIAN}

\section{Mengukur Kecepatan Aliran Sungai}

Sebelum dilakukan penelitian terlebih dahulu di ambil data decepatan aliran sungai supaya diffuser yang di desain sesuai dengan kndisi sungai temat penelitian. Penganbilan data dilakukan di sungai Pintab Desa Tebing Tinggi Kabupaten Balangan Propinsi Kalimantan Selatan. Data kecepatan aliran sungai akan digunakan untuk input data simulasi CFD untuk menguji permodelan diffuser.

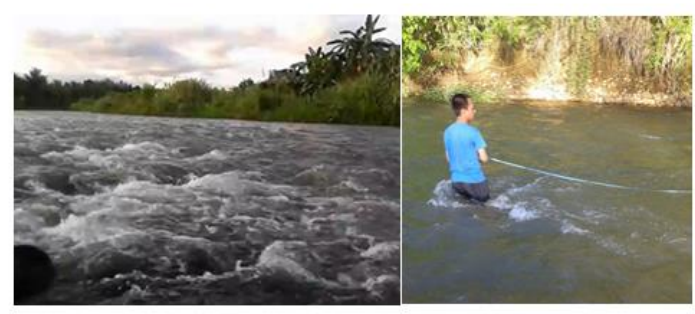

Gambar 1. Pengujian kecepatan aliran sungai Pintab Desa Tebing Tinggi

\section{Model Desain Diffuser.}

Desain defusser berbentuk selubung seperti di jelaskan pada gambar berikut ini di mana di tengahtengah nya dipasang turbin jenis propeler

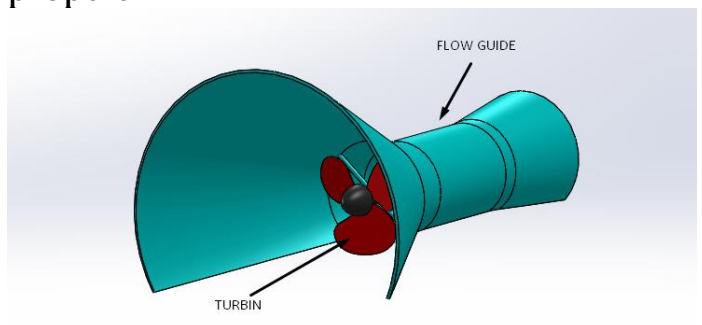

Gambar 2. Model Diffuser

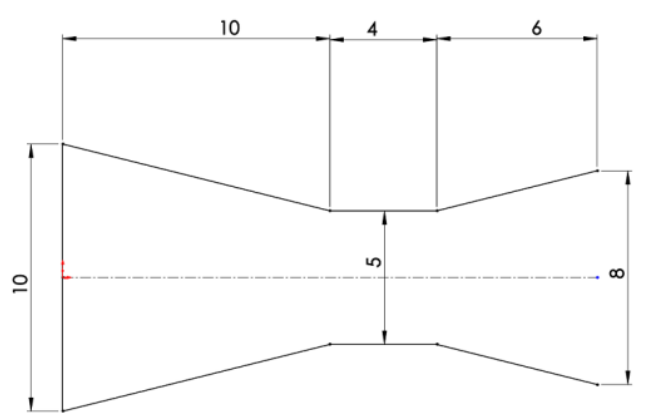

Gambar 3 Diffuser dengan rasio luas $=(\mathrm{Di} / \mathrm{Do})$ $\mathrm{U}=1.25$

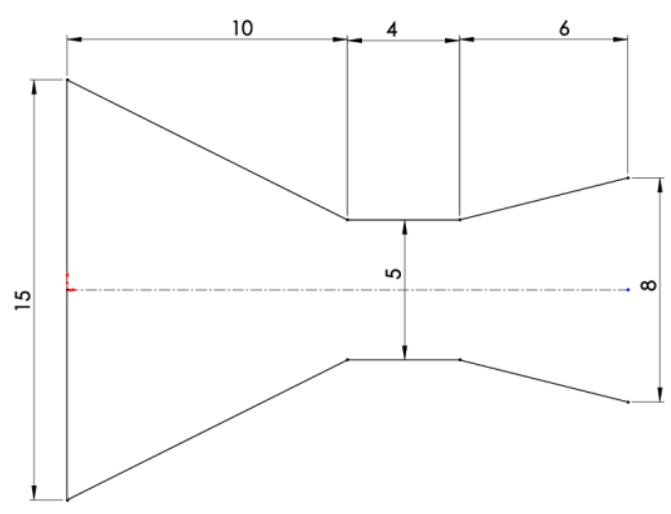

Gambar 4 Diffuser dengan rasio luas $=(\mathrm{Di} / \mathrm{Do})$ $\mathrm{U}=1.875$ 


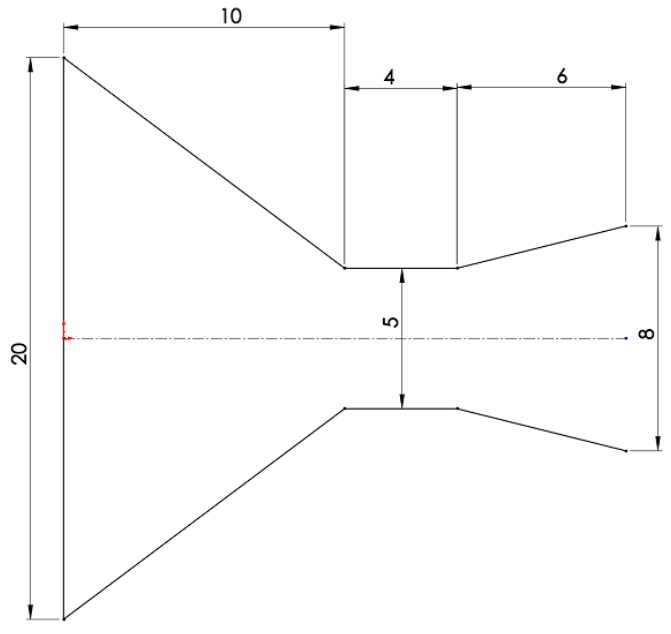

Gambar 5 Diffuser dengan rasio luas $=(\mathrm{Di} / \mathrm{Do})$ $\mathrm{U}=2.5$

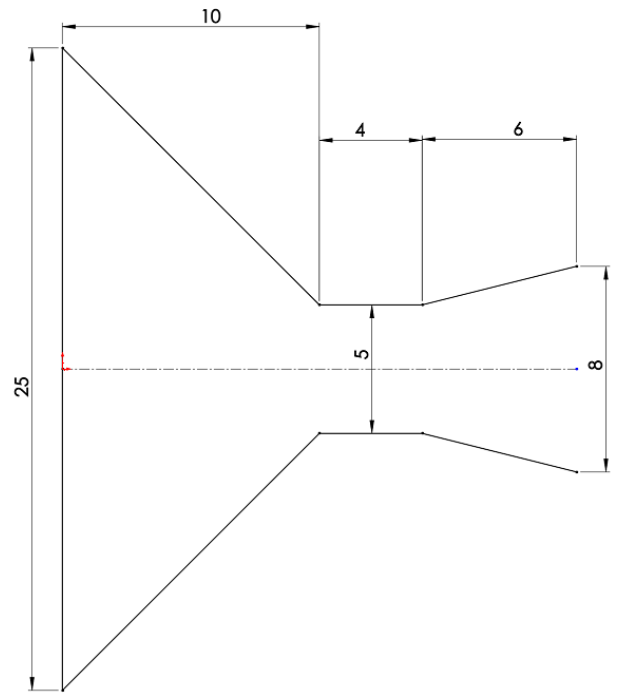

Gambar 6 Diffuser dengan rasio luas $=(\mathrm{Di} / \mathrm{Do})$ $\mathrm{U}=3.125$

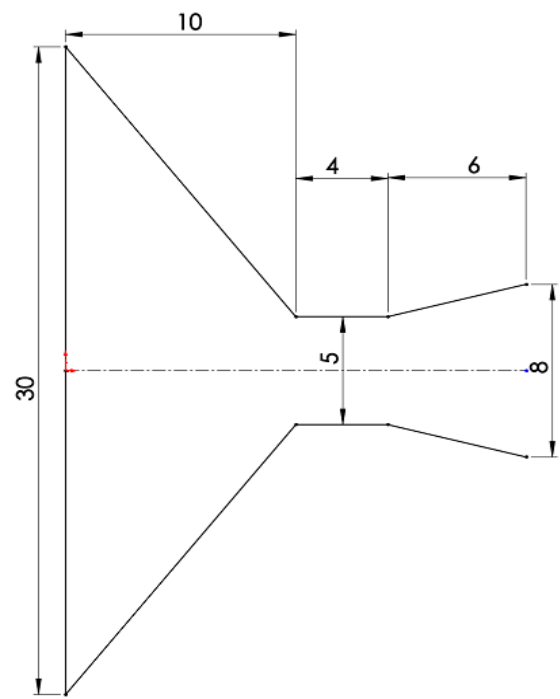

Gambar 7 Diffuser dengan rasio luas $=(\mathrm{Di} / \mathrm{Do})$ $\mathrm{U}=3.75$

\section{Pengujian}

Pengujian dilakukan dengan cara simulasi menggunakan software Ansys. Terdapat tiga tahap dalam simulasi ini : Tahap pertama adalah tahap preprocessing yaitu penggambaran geometri dan meshing (diskritisasi) beserta penentuan kondisi batas pada tiap masing-masing bagian diffuser.

Kondisi Batas

1. dinding sisi tiap sungai : WALL

2. diffuser : WALL

3. Aliran masuk : VELOCITY_INLET

4. Aliran keluar

PRESSURE_OUTLET

5. Volume Sungai : FLUID

6. Volume : FLUID

Tahap kedua merupakan tahap solving yaitu menentukan jenis perhitungan dan persamaan yang digunakan dalam mensimulasikan. Persamaan model viskos yang digunakan adalah k-epsilon dengan kondisi simulasi stedy. Pada tahap terakhir adalah tahap proprocessing adalah tahap mengambil hasil simulasi berupa kontur kecepatan aliran fluida.

\section{HASIL DAN PEMBAHASAN Data Pengujian}

Untuk mengetahui desain yang paling baik dilakukan pengujian. Hasil pengujian di tunjukan pada gambar berikut :

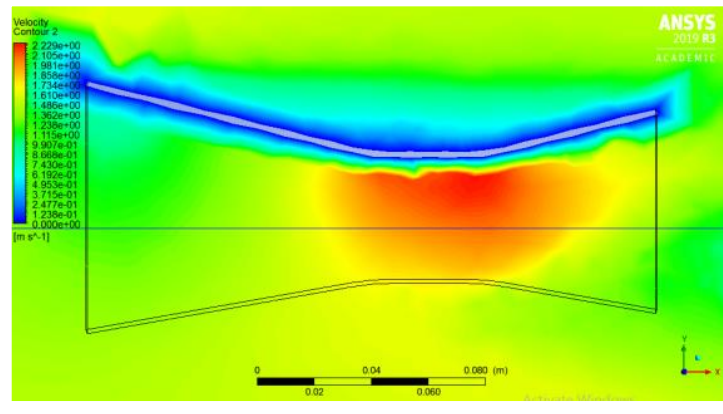

Gambar 8 Countrul Kecepatan Diffuser dengan rasio luas $=(\mathrm{Di} / \mathrm{Do}) \mathrm{U}=1.2$ 


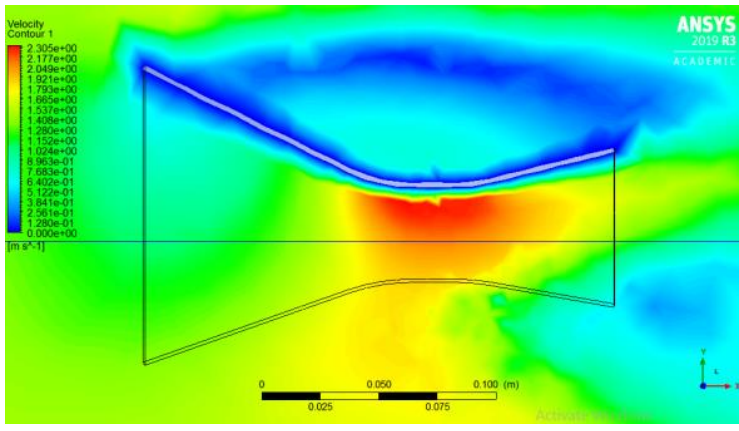

Gambar 9 Countrul Kecepatan Diffuser dengan rasio luas $=(\mathrm{Di} / \mathrm{Do}) \mathrm{U}=1.25$

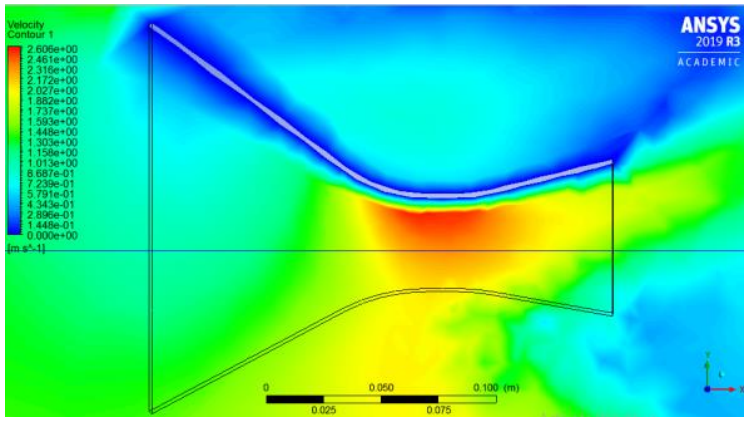

Gambar 10 Countrul Kecepatan Diffuser dengan rasio luas $=(\mathrm{Di} / \mathrm{Do}) \mathrm{U}=2.5$

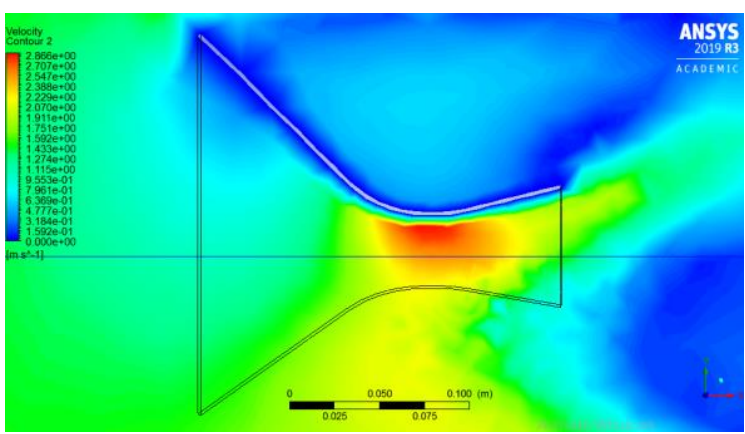

Gambar 11 Countrul Kecepatan Diffuser dengan rasio luas $=(\mathrm{Di} / \mathrm{Do}) \mathrm{U}=3.125$

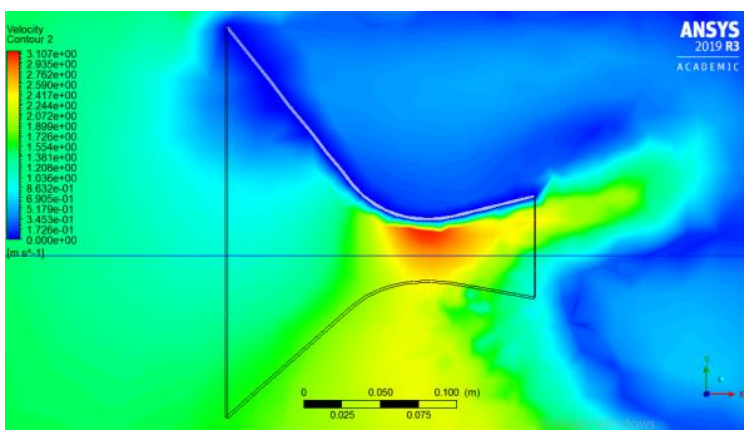

Gambar 12 Countrul Kecepatan Diffuser dengan rasio luas $=(\mathrm{Di} / \mathrm{Do}) \mathrm{U}=1.375$
Dari hasil pengujian yang telah dilakukan dapat dikatakan bawa pemasangan difffuser pada turbin arus sungai dapat meningkatkan kinerja turbin hal ini di dasarkan pada terjadinya peningkatakn kecepatan arus sungai seperti terlihat pada gambar 8 sampai gambar 12. Countrul kecepatan yang berwarna merah menunjukan kecepatan tinggi sedangkan berwarna biru menunjukan kecepatan rendah.

Tabel 1. Rasio Luas (Di/Do) terhadap Velocity $(\mathrm{m} / \mathrm{s})$

\begin{tabular}{|c|c|c|}
\hline $\begin{array}{c}\mathrm{N} \\
\mathrm{o}\end{array}$ & $\begin{array}{c}\text { Rasio Luas } \\
(\mathrm{Di} / \mathrm{Do})\end{array}$ & Velocity $(\mathrm{m} / \mathrm{s})$ \\
\hline 1 & 1.25 & 2.24 \\
\hline 2 & 1.875 & 2.32 \\
\hline 3 & 2.5 & 2.63 \\
\hline 4 & 3.125 & 2.8 \\
\hline 5 & 3.75 & 3.14 \\
\hline
\end{tabular}

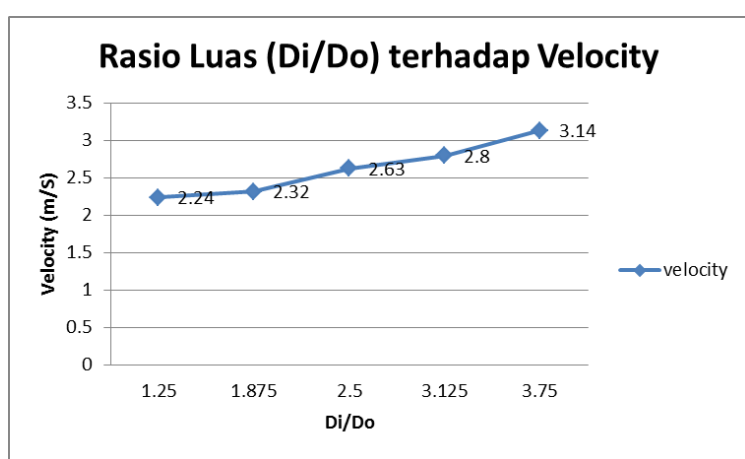

Grafik 1 Perbandingan Rasio Luas (Di/Do) terhadap Velocity $(\mathrm{m} / \mathrm{s})$

Dari tabel dan Grafik 1 menunjukan bahwa Rasio Luas (Di/Do) mempengaruhi kecepatan aliran sungai. Rasio 3.75 memberikan kecepatan aliran sungai paling maksimal yaitu 3.14 


\section{Desain Diffuser}

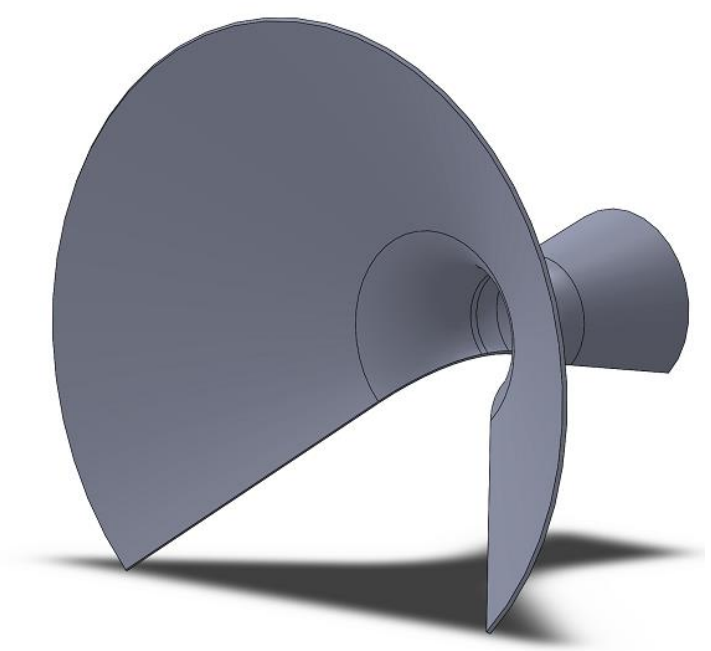

\begin{tabular}{|c|c|c|}
\hline $\begin{array}{c}\mathrm{N} \\
\mathrm{o}\end{array}$ & Parameter & Keterangan \\
\hline 1 & $\begin{array}{c}\text { Rasio Luas } \\
\text { (Di/Do) }\end{array}$ & 3.75 \\
\hline 2 & Potongan & 270 derajat \\
\hline 3 & $\begin{array}{c}\text { Rasio } \\
\text { Diffuser aliran } \\
\text { masuk } \\
\text { L/Di }\end{array}$ & 0.33 \\
\hline 4 & $\begin{array}{c}\text { Rasio Diffuser } \\
\text { aliran keluar } \\
\text { L/Do }\end{array}$ & 0.75 \\
\hline 5 & $\begin{array}{c}\text { Rasio Diffuser } \\
\text { bagian tengah } \\
\text { L/D }\end{array}$ & 0.8 \\
\hline
\end{tabular}

\section{KESIMPULAN}

Desain Diffuser Turbin Air Arus Sungai yang mampu Meningkatkan Laju Arus Aliran Sungai adalah di desain dengan Rasio Luas (Di/Do) adalah 3.75, Potongan 270 derajat, Rasio Diffuser aliran masuk L/Di 0.33, Rasio Diffuser aliran keluar L/Do 0.75 dan Rasio Diffuser bagian tengah L/D 0.8.

\section{REFERENSI}

[1] Rendi, "Analisa Distribusi Tekanan Dan Aliran Disekitar Rotor Savonius Water Turbine," Vol. 02, No. 02, 2017.
[2] Rendi, "Pengaruh Penambahan Nozzle Guide Vane Pada," Vol. 03, No. 02, Pp. 74-79, 2018.

[3] I. Mulkan, R. Hantoro, And G. Nugroho, "Analisa Performansi Turbin Arus Sungai Vertikal Aksis Terhadap Penambahan Variasi Panjang," J. Tek. Pomits, Vol. 1, No. 1, Pp. 1-5, 2012.

[4] A. C. Purnama, R. Hantoro, And G. Nugroho, "Rancang Bangun Turbin Air Sungai Poros Vertikal Tipe Savonius Dengan Menggunakan Pemandu Arah Aliran," J. Tek. Its, Vol. 2, No. 2, Pp. B278-B282, 2013.

[5] Rendi Dan Abdurrahim Sidiq, "Pengaruh Twist Angle Blade Turbin Savonius Berpengarah Aliran Aplikasi Pada Turbin Air," Vol. 19, No. 2, 2019. 